\title{
Phytopathology
}

\section{Advances in Plant Virus Evolution: Translating Evolutionary Insights into Better Disease Management}

\author{
R. Acosta-Leal, S. Duffy, Z. Xiong, R. W. Hammond, and S. F. Elena
}

First author: Texas AgriLife Research (Texas A\&M University System), Amarillo 79106; second author: Siobain Duffy. Department of Ecology, Evolution, and Natural Resources, Rutgers, The State University of New Jersey, 14 College Farm Road, New Brunswick 08901; third author: Division of Plant Pathology and Microbiology, Department of Plant Sciences, University of Arizona, Forbes 303, Tucson 85721; fourth author: U.S. Department of Agriculture-Agricultural Research Service, Molecular Plant Pathology Laboratory, 10300 Baltimore Avenue, Beltsville, MD 20705; and fifth author: Instituto de Biología Molecular y Celular de Plantas (CSIC-UPV), Campus UPV CPI 8E, Ingeniero Fausto Elio s/n, 46022 València, Spain.

Accepted for publication 28 April 2011.

\begin{abstract}
Acosta-Leal, R., Duffy, S., Xiong, Z., Hammond, R. W., and Elena, S. F. 2011. Advances in plant virus evolution: Translating evolutionary insights into better disease management. Phytopathology 101:1136-1148
\end{abstract}

Recent studies in plant virus evolution are revealing that genetic structure and behavior of virus and viroid populations can explain important pathogenic properties of these agents, such as host resistance breakdown, disease severity, and host shifting, among others. Genetic variation is essential for the survival of organisms. The exploration of how these subcellular parasites generate and maintain a certain frequency of mutations at the intra- and inter-host levels is revealing novel molecular virus-plant interactions. They emphasize the role of host environment in the dynamic genetic composition of virus populations. Functional genomics has identified host factors that are transcriptionally altered after virus infections. The analyses of these data by means of systems biology approaches are uncovering critical plant genes specifically targeted by viruses during host adaptation. Also, a next-generation resequencing approach of a whole virus genome is opening new avenues to study virus recombination and the relationships between intra-host virus composition and pathogenesis. Altogether, the analyzed data indicate that systematic disruption of some specific parameters of evolving virus populations could lead to more efficient ways of disease prevention, eradication, or tolerable virus-plant coexistence.

Additional keywords: bottleneck, epistasis, fitness, metagenomics, mutation rate, recombination, robustness, transcriptome.

Corresponding author: R. Acosta-Leal; E-mail address: racostaleal@hotmail.com

doi:10.1094/PHYTO-01-11-0017

(C) 2011 The American Phytopathological Society
Viruses and viroids appear to be the fastest-evolving plant pathogens (39), and cause tremendous economical crop losses annually. Some, such as the single-stranded (ss)DNA begomoviruses, are emergent problems worldwide $(117,126)$. These subcellular pathogens have higher mutation rates than, and distinct evolutionary dynamics from, bacterial and fungal phytopathogens. Understanding their reproductive and transmission strategies - their biology, ecology, and evolution - can lead to insights and interventions for effective crop disease management. This review highlights how viruses and viroids achieve and maintain their unique parasitic lifestyles and how evolutionary virology and systems biology approaches to virus-plant interactions have implications for pathogen control.

The ability of viruses and viroids to change, and to change rapidly, underlies many disease management concerns. Excepting migration from distant locations and other countries, variability in plant pathogen populations is the necessary initial step in adaptation to new plants (host shifting), resistance breaking (RB), and changes in symptoms and virulence. Many times the rise and fall of different genotypes in a population is due to the effects of natural selection: variant genomes that generate more viable descendants become more frequent over time. This process can be sped up or inhibited by bottlenecks (Box 1 provides definitions of terms in bold), that plant pathogens experience as they move from cell to cell and from plant to plant $(57,69,88)$. To expand its host range, a virus population must already have a variant (perhaps at a very low level in the population) that can infect that potential host. In the novel host, those mutants will be fitter and will rise in frequency. However, in the absence of selection on that novel host, the only chance that neutral host range mutations have to be fixed in the population is by genetic drift. Otherwise, neutral or even deleterious mutations will be removed by purifying selection. Understanding the processes that generate viral diversity and the ecological processes that determine selective pressures and bottlenecks can illuminate potential interventions or determine where and when control measures might be most effective.

Mechanisms of virus and viroid genetic variation. Viruses have several ways to achieve variation within a plant and within a 
field. First and foremost is mutation: the imperfect copying of genomic material from parent to offspring and subsequent chemical and enzymatic changes to nucleotide bases. RNA viruses are notorious for having high mutation rates, due to replication with RNA-dependent polymerases lacking proofreading activity. The polymerases of large nidoviruses are an exception (100), but none have yet been shown to infect plants. Most studies of plant virus variation measure mutation frequencies over a range of time, such as viral mutations arising within a month after plant infection. These studies are popular in plant virology because of the difficulty in relating mutation frequency to how often the viruses have replicated their genome within a whole plant. Despite this limitation, mutation frequencies can be used to estimate upper boundaries on plant viral mutation rates (reviewed in literature citation 120). Mutation rate studies tally the mutations produced prior to the action of selection, either per round of genomic replication or per cell infected. Two exceptional studies have calculated mutation rates: one for Tobacco mosaic virus (TMV) (94) and the other for Tobacco etch virus (TEV) (135). In both cases, the mutation rates trend toward the lower end of measured animal and bacterial RNA virus rates (Fig. 1).

Plant RNA viruses may indeed have lower mutation rates than animal RNA viruses, but the existing data show that they are not substantially lower, and some of the differences could result from methodological dissimilarities. In fact, some plant pathogens do mutate faster than animal RNA viruses: plant viroids, for instance, have the highest per-base mutation rate yet measured for any disease-causing agent at $2.5 \times 10^{-3}$ per base per round of replication
(61) (Fig. 1). Despite this highest per-base mutation rate, viroids seem to obey the constant of around one mutation per replicated genome reported by Drake et al. (36) for most RNA viruses. This fairly constant per-genome mutation rate suggests that RNA genome sizes are limited by their individual per-base mutation rates. Otherwise, a larger genome replicated with a given per-base mutation rate, for example, a closterovirus with the per-base mutation rate of a viroid, would be unable to maintain functional elements because of the accumulation of too many mutations in its genes. Thus, a population of such larger genomes would collapse due to lethal mutagenesis (17). Recombination may play a significant role in the virus survival by reducing the amount of deleterious mutations incorporated in the same virus genome.

Viroids are the smallest known pathogenic agents of plants and cause diseases of considerable economic importance $(33,34)$. Viroid genomes are composed of a single-stranded, self-complementary RNA molecule of 246 to 475 nucleotides. Viroids lack the capacity to code for proteins, are not encapsidated, and are replicated by host-encoded polymerases (32). They are classified into two families: those that replicate in the nucleus (Pospiviroidae) and those that replicate in the chloroplast (Avsunviroidae) (28). The most abundant pospiviroids are characterized by the presence of a central conserved region, absence of hammerhead ribozymes, and nuclear replication via an asymmetric rolling circle by a nuclear DNA-dependent RNA polymerase II. Avsunviroids are characterized by the absence of a central conserved region, the presence of a hammerhead ribozyme, and replication in the chloroplast via a symmetric rolling circle by another

\section{BOX 1}

Definitions of some important terms

\begin{tabular}{|c|c|}
\hline Complementation & The rescue of loss-of-function mutants by functional alleles contained in the population. \\
\hline Effective population size $\left(N_{e}\right)$ & Number of individuals capable of producing viable progeny. \\
\hline Epistasis & $\begin{array}{l}\text { The effect of a mutation in one gene over the expression of another gene or mutation of the } \\
\text { same genome. }\end{array}$ \\
\hline Genetic bottleneck & A severe reduction in population size. \\
\hline Genetic drift & $\begin{array}{l}\text { Changes in the genetic structure of a population caused by random sampling of haplotypes } \\
\text { moving from generation to generation. }\end{array}$ \\
\hline Host range mutation & A mutation that affects the host range of a parasite. \\
\hline Interference & Competition between beneficial mutations to become fixed in the population. \\
\hline Lethal mutagenesis & Excessive accumulation of mutations in a population that causes population extinction. \\
\hline Multiplicity of cellular infection (MOI) & Relative number of infectious particles that penetrate a cell. \\
\hline Mutation frequency & Proportion of mutations in a population remaining after the action of selection. \\
\hline Mutation rate & Proportion of mutations in a population that accumulate prior to the action of host selection. \\
\hline Mutation-selection balance & $\begin{array}{l}\text { The coupling between mutation rate and selection pressures that define the frequency of } \\
\text { mutations in a population. }\end{array}$ \\
\hline Nucleotide diversity ( $\pi)$ & $\begin{array}{l}\text { Average number of nucleotide differences per site between any two randomly chosen } \\
\text { haplotypes from a population. }\end{array}$ \\
\hline Positive selection & Selection of adaptive mutations. \\
\hline Purifying (negative) selection & Conditions that favor the removal of deleterious mutations from the population. \\
\hline Robustness & $\begin{array}{l}\text { Molecular mechanisms that allow for the accumulation of mutations without concomitant } \\
\text { phenotypic change. }\end{array}$ \\
\hline
\end{tabular}


nuclear-encoded chloroplast DNA-dependent RNA polymerase. Whereas pospiviroids are predicted to be primarily rod-shaped, avsunviroids are predicted to be more highly branched structures. Thus, viroid molecules are a collection of structural-sequence motifs that interact with host components for viroid replication, processing, transport, and pathogenesis that may all influence viroid evolution (153). Avsunviroids populations appear to have more haplotypes than pospiviroids (26). It has been estimated that the mutation rate of avsunviroids is 10-fold larger than for pospiviroids $(41,46)$. Apparently, most mutations in the rodlike structure of pospiviroids are deleterious. In fact, many stable mutations of viroid genomes map in loops or as compensatory mutations in hairpins and stems $(9,30)$.

Therefore, how viroids achieve the highest mutation rates among the known infectious RNAs observed in nature is still a matter of speculation. Viroids are replicated by DNA-dependent RNA polymerases with variable proofreading efficiencies. Even more, when these enzymes use RNA instead of native DNA as template, their replicative fidelity could be further reduced. Another putative mechanism, by which viroid and viral mutation rates could be elevated above that of the polymerase error, is through enzymatic changes to nucleotide bases. Cytidine deaminases are enzymes that turn cytidine (C) into uridine (U), and mammals use a family of them (APOBEC) as antiviral defense against some viruses (73). Plants have orthologous proteins that have known roles in posttranscriptional modification, and they are most active in mitochondria and chloroplasts (24). It may be the case that these plant enzymes can be active on virus and viroid RNA as well, which would increase $\mathrm{C} \rightarrow \mathrm{U}$ substitution rates. Other deaminases increase substitutions such as $\mathrm{A} \rightarrow \mathrm{I}$ (adenosine to inosine). Patterns of frequent cytosine deamination have also been detected during ssDNA geminivirus evolution (37). This could be due to these enzymes reacting with ssDNA viral genomes, but $\mathrm{C} \rightarrow \mathrm{U}$ is also the most common kind of spontaneous chemical degradation that can occur on unpaired nucleotides so cytosine transitions could be increased solely because geminiviral DNA is frequently single-stranded.

Substantial virus and viroid diversity is generated in plants also by homologous and heterologous recombination. Pathogens often co-infect the same plant, allowing co-infection of single cells (102), and some viruses frequently take the opportunity to unequally exchange genes $(23,66,87)$. While recombinants mostly appear to be tolerated between conspecific viruses, intergenus recombination is also possible, and recombination can even lead to incorporation of host genetic material. Recombination rates are difficult to measure, but could be as high as mutation rates: Brome mosaic virus could exhibit an homologous crossover event per RNA molecule per replication cycle (139), Cauliflower mosaic virus (CaMV) has an estimated recombination rate of around $2 \times$ $10^{-5}$ per round of replication (59). It has been proposed that recombination may have led to the emergence of mosaic sequences from viroids co-infecting the same host $(74,106)$. Recombinants have been associated with altered host range and virulence (107). One clear example of a virulent recombinant was a hybrid of East African cassava mosaic virus and African cassava mosaic virus (ACMV) that overcame crop resistance to ACMV and decimated cassava production in Uganda in 1997 (113).

Plant viruses evolve quickly. The speed of evolution can be estimated by the rate at which the genetic makeup of a population changes in time by selection and/or genetic drift. Representatives of the RNA families Potyviridae (67,127), Tobamoviridae (108), and a sobemovirus (52), and the ssDNA families Geminiviridae $(37,38,75)$ and Nanoviridae (70) evolve faster than $10^{-5}$ fixed nucleotide substitutions/site/year (s/s/y), and as high as $10^{-3} \mathrm{~s} / \mathrm{s} / \mathrm{y}$. There does not appear to be a distinction between the evolution rate of plant versus animal viruses $(39,65)$, and between RNA and ssDNA viral substitution rates in plants: all plant viruses appear to be fast-evolving.

These results were initially at odds with the plant virus evolution literature, which stressed overall genetic stability over time, especially in comparison to viruses of animals with adaptive immune systems $(63,66,149)$. Indeed, substantial purifying selection exists for plant viruses to maintain nucleotide or amino acid sequences that reduce nucleotide substitution rates. One wellestablished source of purifying selection is the alternation in selective pressures that vectored viruses experience when cycling between animal and plant cells. The capsid proteins of these viruses, which interact with both host and vector, are under more pressure to be unchanging, as evidenced by very low ratios of the rate of nonsynonymous changes to the rate of synonymous changes $\left(d_{N} / d_{S}\right)(22)$. This purifying selection also leads to lower average rates of capsid gene evolution in vectored animal viruses than in directly transmitted viruses (79). Still, the measured and estimated high nucleotide substitution rates of plant viruses occurs in the presence of purifying selection, and the evolutionary rate of vectored plant viruses is within the same order of magnitude as some directly transmitted viruses. But an important point to stress is that these rates of evolution are usually calculated over many years, if not decades, and reflect an average nucleotide substitution rate. As will be shown in a subsequent section, rates of mutation fixation can be higher when viruses are under positive selection, such as when they are adapting to a novel host plant, and several beneficial mutations may become ascendant in a short period of time.

Variability sometimes leads to adaptability. The average mutation and the average recombination event are deleterious, and
FIGURE 1

Average mutation rates (mutations per base per infected cell, except as noted) of viruses and viroids with RNA and single-stranded (ss)DNA genomic architectures. The rates of two plant RNA viruses are shown as green squares:

Tobacco mosaic virus (94) and Tobacco etch virus (135).

Mutation rates of one RNA bacteriophage and eight RNA animal viruses are shown as orange squares (measles virus'

mutation rate is given as mutations per base per genomic replication event and cannot be extrapolated to cell infected) (125). Similarly, the per base per genomic replication event mutation rate of Chrysanthemum chlorotic mottle viroid is shown as the green triangle. Two measured mutation rates of ssDNA bacteriophages are shown as blue squares. Rates are from Sanjuán et al. (123) and references therein.

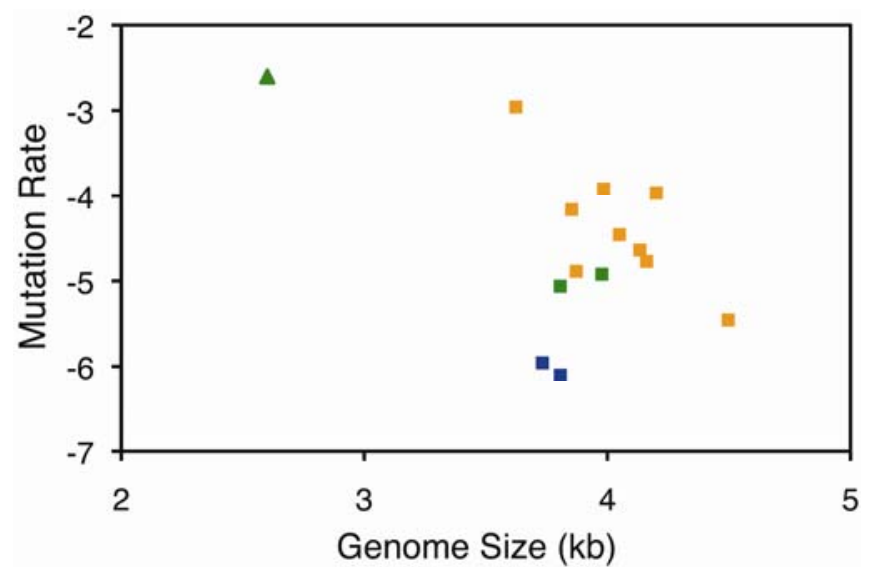


many are lethal. Around $70 \%$ of mutations are deleterious $(20,35$, 122). Consequently, variants that are produced are not always maintained in viral populations. However, some of those changes that are deleterious in the current host and environment may be adaptive under different conditions (40,53). Therefore, mutations that are deleterious in the current host will be maintained in a population if they are either mildly deleterious (nearlyneutral), if they are continually created by new mutational events, or at a ratio of these two factors called the mutation-selection balance.

The mutation-selection balance is one, but not the only factor determining whether a mutation will be part of a virus population. Complementation between co-infecting viruses can result in viral genomes carrying deleterious, even lethal, mutations being maintained in populations (60). Plant viruses can even develop defective interfering genomes that require at least one essential component or function be supplied in trans by another virus genome (90). Viral proteins that generally are shared among particles are involved in coating, cell-to-cell movement, and suppression of gene silencing, but many other proteins may operate in trans exclusively in some virus species. Defective interfering genomes are distinct from satellite viruses, which rely on complementation but do not descend from the helper virus. Many satellites attenuate the effects of the primary virus infection (128), but a minority can increase virulence, such as the beta satellites of ssDNA begomoviruses (16). Similarly, defective interfering genomes modulate infection severity, often competing with the complementing virus and reducing virulence $(111,128)$.

Maintaining population variability is what allows for the chance encounter between a novel environment and a mutation that is beneficial in that environment, such as a host range mutation. However, high variability does not necessarily indicate great adaptive potential. For instance, genetic robustness is based on a number of buffering mechanisms (including genetic redundancy and cellular chaperones) that minimize mutational effects (44). Since plant viruses and viroids mutate so frequently, and the vast majority of mutations are deleterious, robustness is often a successful evolutionary strategy. The empirical demonstration of robustness operating in an infectious RNA was provided by Codoñer et al. (26). They designed a co-infecting competition experiment for this purpose. In this experiment, slow replicating and highly heterogeneous populations of an avsunviroid outcompeted fast replicating and relatively homogeneous pospiviroid populations only when the mutation rates of both viroids were artificially increased by UV irradiation. Thus, under such conditions, the highly heterogeneous viroid populations were more adapted. Whether the increased robustness in the avsunviroid is due to its more relaxed RNA secondary structure or its higher genetic heterogeneity is still unknown.

Eventually, even robust genomes will show effects due to the numerous mutations accumulated in their genomes, but it is in unpredictable ways. The accumulated mutations may together cause large drops in fitness, even though some individual genotypes may be adaptive in the current host (18). Additionally, robustness is often specific to a virus in a particular environment. Shifting to another host can cause plant viruses to be less robust, and show the effects of their accumulated genetic diversity and subsequent mutations. The relationship between robustness and the ability to evolve and adapt is complex and murky (99). Further complicating the practical interpretation of viral and viroid genetic diversity, robustness does not explain all examples where greater variability fails to lead to greater adaptability. Despite the greater robustness of an avsunviroid mentioned above, members of this family generally infect fewer hosts, appear to host-shift less often, and have more restricted host ranges than pospiviroids
(41). Therefore, more research is required into the evolution of a wide variety of plant subcellular pathogens to understand the interplay between genetic heterogeneity of the population and adaptation.

\section{EPIDEMIOLOGICAL DYNAMICS OF VIRUS POPULATIONS}

A premise in virus evolution is that the dynamic genetic structure of virus populations has a significant role in virulence, epidemiological progression of the disease, and host shifting among other biological properties of viruses (76). How the mechanisms mentioned above regulate the genetic structure (i.e., number and frequency of haplotypes, and genetic distances among them) of virus populations at the intra- and inter-host levels and their biological relevance are presented in this section.

Dynamics of the INTRA-host genetic structure of plant virus populations. Theoretically, the structure of an active virus population changes within a host individual during the course of a systemic infection. Despite the random emergence of spontaneous mutations, these structural changes could exhibit deterministic or stochastic behavior (118). The former has been observed primarily in compatible virus-plant interactions (i.e., between virulent pathogen and susceptible host), whereas stochastic population structures are more frequently generated in incompatible interactions (i.e., avirulent pathogen and resistant host) or during viral host adaptation. Intra-host populations of Tobacco mild green mosaic virus, despite their heterogeneous composition, exhibit high genetic stability in field infections of Nicotiana glauca $(55,103,115)$. High genetic stability also appears to be the norm in several other plant viruses infecting their compatible hosts (reviewed in Literature citation 63). This relative genetic stability suggests that virus populations might not undergo substantial changes while they are interacting with their natural host genotype. Purifying selection affecting the $d_{N} / d_{S}$ ratio in the order of 0.01 to 0.31 has been found to operate in highly adapted virus populations, maintaining them in equilibrium (62). The mutation frequency of plant viruses are influenced by host species (124). Recently, a comparative bioassay of Beet necrotic yellow vein virus (BNYVV) infecting compatible versus incompatible host genotypes demonstrated that more variability exists in small BNYVV populations from partially resistant plants than in large populations produced in susceptible hosts (1). These data agree with the high genetic stability of BNYVV prevailing worldwide during long periods in susceptible sugar beet cultivars and the sudden stochastic diversification of BNYVV observed after the deployment of resistant genotypes in the field $(2,85)$. Similarly, for other plant viruses, higher diversity has been recorded at their centers of origin, where the plant virus presumably initiated its adaptation to a new host $(51,104,133)$.

Without external input variation by superinfections, the increase in the intra-host genetic diversity that some plant virus populations experience under restrictive host conditions is most likely the result from deviations of the mutation-selection balance. Accumulating evidence indicates that mutation rate, rather than an invariable property of the virus, may fluctuate in response to changes in viral replicase and specific cellular conditions $(39,47)$. For instance, the terms mutators and antimutators have been coined for individuals within a species that have an inheritable higher or lower mutation rate than the wild type, respectively (95). They have been discovered in bacteria, bacteriophages, and human viruses (reviewed in Literature citation 129). Individuals encoding each one of these mutational phenotypes might coexist in the same intra-host population and, under some conditions, one will eventually predominate. Although neither a plant virus nor a viroid isolate has exhibited mutator or anti- 
mutator phenotypes, greater than usual mutation frequencies have been detected for Potato virus $Y$ (PVY) and BNYVV only under restrictive host environments $(1,4)$.

Once mutations have been introduced in a virus population, their frequency is regulated by their interactions with other existing mutations $(43,121)$. Epistasis, the interaction between different loci of the same genome, can be antagonistic or synergistic depending on its effect on fitness (76). Antagonistic epistasis means that two deleterious or beneficial mutations can be, respectively, not as bad or as good in combination as expected by combining their individual fitness effects. Synergistic epistasis, on the other hand, enlarges the total fitness effect of the interacting mutations. Given the extreme genome compactness, gene overlapping, and lack of genetic redundancy, most mutations in virus genomes show antagonistic epistasis (20). Coincidently, viral genome architectures that favor antagonistic epistasis are less robust to spontaneous mutations than those with greater synergistic epistasis (44). Whereas epistatic interactions generally regulate the frequency of cis-acting mutations, complementation and interference regulate in trans the frequency and prevalence of mutants into the infecting virus population (60). The genetic structure that results from the combined action of all of these interactions, rather than specific genotypes composing the population, could be the target of selection.

Dynamics of the INTER-host diversity of virus populations. The largest amount of genetic data available on plant virus populations is for the inter-host level. The data could be from individual or pooled plant samples and, typically, it is represented by consensus sequences of a specific region of the virus genome. One of the most striking observations derived from these data is the apparent differentiation between fully host-adapted and hostadapting virus populations. In both of these types of compatible virus-plant interactions, viruses reach high titers in infected plants, but in host-adapted populations the genetic diversity among isolates is several orders of magnitude lower than in hostadapting populations. The genetic diversification of Wheat streak mosaic virus (WSMV) can be used as a reference point for the rate of plant virus evolution. Phylogenetic analysis of 54 WSMV field isolates from North America suggests that they arose from a common ancestor introduced nearly a hundred years ago. The number of segregating polymorphic sites in this representative population was 0.047 and the mean pairwise nucleotide diversity (т) 0.020 (130). Phylogeographic studies of Rice yellow mottle virus (RYMV) infecting rice crops in Africa pinpointed the center of origin of RYMV to eastern Tanzania from where it migrated northwest up the west coast of Africa (51). The largest RYMV inter-host $\pi$ per square kilometer occurs in Tanzania (i.e., around 200 times greater than in any other region of the continent) without a correlation with the diversity of its potential host species (114). Therefore, it is likely that the high RYMV diversification in Tanzania may have resulted from disruptions of the mutation selection-balance that initially took place at the intrahost level and then among adapting isolates. Similarly, around 240 times greater BNYVV nucleotide diversity was detected between RB variants recently emerging in the Imperial Valley of California $(\pi=0.0024)$ than wild type isolates collected nationwide $(\pi=0.00001)(3)$. Other factors that could be correlated with the magnitude of inter-host virus diversity are the genetic diversity of the host, frequency of superinfections, transmission mechanisms, etc. However, other than greater virus diversity detected in sexual compared with asexual host genotypes (105), the effects that those variables may have on plant virus populations apparently have not been explored.

Relationships between INTRA- and INTER-host virus diversity. Except for those viruses where mechanical inoculation is part of their mode of transmission in the field $(11,116)$, limited data exist concerning the intra- and inter-host genetic structure of vector-transmitted virus populations. These are some of the few available examples where the population was not mechanically inoculated prior to the analysis, which may disturb the natural structure. The $\pi$ value of whitefly-transmitted isolates of Cucumber vein yellowing virus was around 0.0005 among clones from two single-plant populations and 3.4 times greater among 56 consensus sequences (78). Similarly, Vives et al. (142) found that the intra-host $\pi$ of Citrus leaf blotch virus in 37 citrus trees naturally infected (unknown vector) in a region of Spain, was three to four times lower than the inter-host $\pi$. Theoretical analyses indicate that greater genetic diversities between (i.e., $\pi_{B}$ ) rather than within (i.e., $\Pi_{W}$ ) single-plant populations is favored by random genetic drift during virus propagation (62). If genetic drift occurs more frequently at suboptimal virus fitness because $\Pi_{W}$ is higher than at optimal fitness, then, it is expected that the $\pi_{W} / \pi_{B}$ ratio of virus populations will be related to virus fitness as described in Figure 2. In this way, the ratio $\pi_{W} / \Pi_{B}$ could reflect the level of viral host adaptation. Initial support for this model has been obtained by comparing the nucleotide diversities of BNYVV populations from composite samples of resistant $R z l$ sugar beets (3). Pooled samples apparently are more reliable for this type of analysis because they minimize the intrinsic plant-to-plant variation. This analysis revealed that, while BNYVV titers are $10^{2}$ to $10^{4}$ times higher in symptomatic plants infected by emerging RB variants than asymptomatic plants infected by avirulent virus populations, the opposite occurs in relation with the $\pi_{W} / \pi_{B}$ ratio. It was 7.8 to 12.2 times larger in asymptomatic than symptomatic resistant plants (i.e., $\Pi_{W} / \pi_{B}=6.1$ to 16.7 versus 0.5 to 2.1 , respectively).

Population bottleneck as an additional modulator of genetic diversity. Sustaining variation is a particular challenge for plant viruses because severe genetic bottlenecks exist as vectored viruses move from plant to plant and even within plants. Population bottlenecks can occur during vector inoculation, cell-to-cell movement, vascular access, vascular transport, vascular exit, specific tissue entry (i.e., lateral roots, endosperm, meristems, etc.), vector acquisition, viruliferous vector migration, and alternate host infections $(57,88)$. These conditions create spatial structure in how the virus diversity is distributed throughout the plant and the field. Within each new plant or portion of a plant, a viral population regains diversity as it multiplies from a small initial number of infecting genomes. After repeated host-tohost transfers of WSMV, similar numbers of haplotypes were found whether one or two strains initially infected the plant (58). Thus, bottleneck size during virus transmission is not always correlated with the extent of regained variability in the derived population.

The multiplicity of cellular infection (MOI) has been developed as a way of estimating the number of virus genomes that invade a plant cell during the course of local and systemic virus infections. The first reported MOI of a plant virus was provided by González-Jara et al. (69). They estimated that approximately six TMV genomes initially infect Nicotiana benthamiana cells. Then, the MOI decreases to one to two genomes during the systemic infection process suggesting the involvement of mechanisms inhibiting superinfection at the advanced stages of the disease. Similarly, MOI of five to six genomes were estimated for Soil-borne wheat mosaic virus causing localized leaf infections in Chenopodium quinoa (101). MOI values around four, with a maximum of 13 during the acute phase of systemic infection, were calculated for CaMV infecting its natural host, Brassica rapa (72). In general, the estimation of cellular MOI requires viral genomes carrying specific neutral mutations or reporter genes to monitor the frequency and location of single and mixed infected cells. Newly generated mutant genomes 
that may have derived from the inoculated transcripts are not considered in these calculations, neither are virus genomes that may have been silenced or partially expressed. Therefore, MOI values, rather than being an absolute number, may represent a fraction of a larger and still unknown number of viral genomes per cell.

Theoretical analysis of the data presented above indicates that bottleneck size is critical in preserving the parental population structure including both adaptive and defective mutants. For instance, in virus populations where lethal mutants can only be maintained by trans-complementation by functional virus genes, the chances that these selfish mutants will predominate in the following generation are greater with broader bottlenecks because it increases the probabilities of co-infecting with fitted virus genomes (101). With narrow bottlenecks, on the other hand, only fit genomes will infect most of the cells and consequently the genetic diversity is expected to decrease by leaving behind defective mutants. For mutants that can replicate by themselves, however, the opposite outcome is more likely, i.e., the genetic diversity is expected to increase at smaller bottleneck sizes because low frequency neutral or near neutral mutants have better chances of moving forward by random drift and infect neighboring cells by themselves. With broader bottlenecks, by contrast, the parental population structure has more probabilities of being reproduced in most of the infected cells.

The impact that different levels of intercellular bottlenecks may have on the genetic structure of ensuing virus populations has not been empirically determined, but coincidental data suggest that it could be extremely important for disease management. For instance, two resistant tobacco genotypes with the same barrier to PVY cell-to-cell movement but different levels of cellular virus accumulation exhibit drastic differences in the incidence of spontaneous RB infections (4). The tobacco with the weak resistance durability, NC745, has larger PVY populations in the initially infected cells than the near immune tobacco VAM. Consequently, the proportion of particles moving from one cell to the next is smaller in NC745. Thus, although the absolute number of moving viral particles might be the same in both tobacco genotypes the proportions are not. This observation suggests that relative rather than absolute MOI values could be a more reliable estimation of the effect of bottlenecking on plant resistance durability.

\section{THE SYSTEM BIOLOGY APPROACH}

Systems biology (SB) allows assessing gene expression at a genome-wide scale, providing unprecedented views of the virushost interaction. SB deals with the study of interactions between components of biological systems and how these interactions give rise to the function and behavior of the system $(14,84)$.

To complete their infectious cycle, the few viral components must establish multiple and complex interactions among themselves $(54,71,89,138)$ as well as with a large number of components from the host $(13,132,146)$. These interactions result either in the plant controlling the infection or in the virus overcoming defenses and establishing a systemic infection. Indeed, the recent application of the SB approach to the analysis of virus-host interactions has revealed a more complete picture of the sets of host factors required for virus infection $(86,146)$. Moreover, SB has uncovered highly connected host genes that operate as central elements in the plant regulatory network and are specifically targeted by viruses to control the host metabolism $(19,29,42)$. Additionally, SB has revealed topological changes of the intraviral interaction network that are caused by its integration within the host network $(93,137)$.

While the SB approach has been increasingly used in the analysis of animal virus-host interactions (e.g., hepatitis C, human immunodeficiency, yellow fever, influenza A, or herpesviruses), plant virology has not yet benefitted to the same extent, and the most relevant studies in the field generally apply transcriptomic techniques to generate lists of genes with altered mRNA abundance in infected plants. However, the proper network analysis of virus-plant interaction is still a pending task (45).

Different viruses, common targets. Although some studies have analyzed changes in mRNA profiles resulting from viruses infecting their natural hosts, such as ACMV infecting cassava (56) or RYMV infecting rice (141), Arabidopsis thaliana has been extensively used as a model host in combination with viruses belonging to different taxonomic families (Table 1). However, even using the same host species, direct comparison across experiments is not straightforward because differences in profiling techniques and platforms, plant ecotypes, sampling schemes, inoculation conditions and dosages, and environmental variables

\begin{abstract}
FIGURE 2
Model of the relationships between virus fitness and nucleotide diversity of virus populations at the intra- $\left(\pi_{W}\right)$ and inter $\left(\pi_{B}\right)$ isolate levels along virus host adaptation. The arrow represents the direction of the evolutionary steps followed by a virus adapting to a new host genotype (time scales could be

significantly different in each one of the four represented evolutionary phases). The intermediate adapting phase is subdivided into an initial genetically incompatible virus-plant interaction and a subsequent compatible interaction at which host resistance has been genetically defeated. Virus adaptations in the old and new hosts are characterized by the lowest $\pi_{B}$ and highest virus fitness.
\end{abstract}

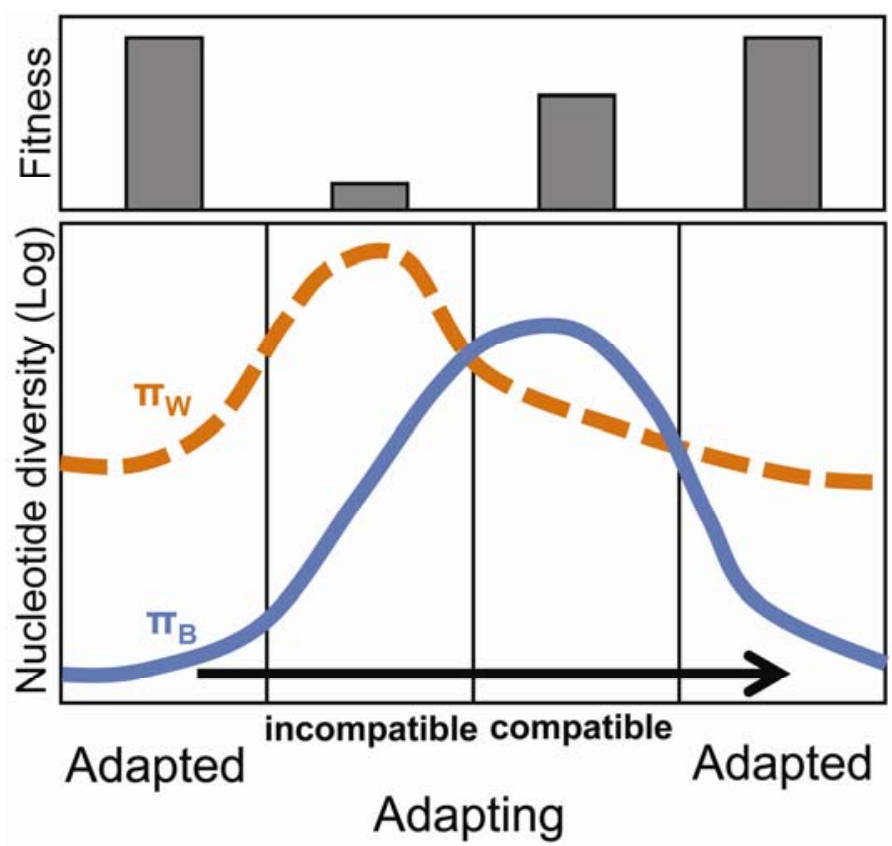

Vol. 101, No. 10, 2011 
may all exert some unpredictable effects on the expression pattern of multiple genes.

Whitham et al. (145) carried out the most comprehensive of such studies, including five viruses mentioned in Table 1 (Cucumber mosaic virus [CMV], Oilseed rape mosaic virus [ORMV], Potato virus $X[\mathrm{PVX}]$, Turnip vein clearing virus [TVCV], and Turnip mosaic virus [TuMV]) while keeping all other experimental variables and techniques constant. Some generalities were drawn from this study that are extensible to most of the other studies listed in Table 1. First, approximately one-third of overexpressed plant genes are associated with cell responses to situations of stress, defense against infection, apoptosis, programmed cell death, and ageing. Second, defenselike responses of $A$. thaliana to viruses are dependent on salicylic acid (SA) and require upstream signaling components (148). Third, a spectrum of heat-shock proteins (HSP) is also induced after infection with all viruses by a yet unknown SA-independent mechanism. HSP overexpression may be a generic unspecific response of the plant to stress or, alternatively, directly triggered and controlled by viruses to assist in the correct folding of their own proteins, many of which may be misfolded (and thus aggregating) as a consequence of mutations produced during replication (80). Fourth, cell wall modification genes are preferentially down-regulated. Because the expression of these genes is correlated with plant cell growth and expansion, their reduced expression may well result in the stunting syndrome associated with some infections. Fifth, similarly, plastid genes and genes involved in chloroplast functioning are also preferentially downregulated, resulting in chlorotic symptoms. Sixth, ribosomal proteins and protein turnover genes are up-regulated. This may either reflect an increased demand on the cells for protein synthesis or a response triggered by viruses to enhance their own replication.

Host-adaptation and changes in gene expression profiles. The actual interactions between viruses, natural hosts, and vectors are the results of natural selection operating during many generations. Hence, to have a precise description of the interactions established between viral and cellular components, it is necessary to take into account the evolutionary perspective of the process: the degree of adaptation of the virus to its host. Unfortunately,

TABLE 1

Studies of gene expression global profiling

for Arabidopsis thaliana in response to viral infection

\begin{tabular}{llc}
\hline Virus genus & \multicolumn{1}{c}{ Virus species } & Reference \\
\hline Caulimovirus & Cauliflower mosaic virus (CaMV) & $(64)$ \\
\hline Cucumovirus & Cucumber mosaic virus (CMV) & $(77,96,145)$ \\
\hline Geminivirus & $\begin{array}{l}\text { Mung bean yellow mosaic virus } \\
\text { (MYMV) }\end{array}$ & $(134)$ \\
\hline Potexvirus & Pabbage leaf curl virus (CaLCuV) & $(10)$ \\
\hline Potyvirus & Turnip mosaic virus (TuMV) & $(145)$ \\
\hline & Plum pox virus (PPV) & $(145,151)$ \\
\hline & Tobacco etch virus (TEV) & $(5)$ \\
\hline Tobamovirus & Turnip vein clearing virus (TVCV) & $(145)$ \\
\hline & Oilseed rape mosaic virus (ORMV) & $(145)$ \\
\hline & Tobacco mosaic virus (TMV) & $(48,68)$ \\
\hline
\end{tabular}

this evolutionary perspective has not been taken in most studies listed in Table 1: only TuMV, CMV, and CaMV are prevalent in wild A. thaliana populations (109).

To test whether adaptation to a host may result in changes in mRNA profiles, Agudelo-Romero et al. (6) performed an evolution experiment adapting TEV to ecotype Ler-0 of A. thaliana (25). The TEV clone used as the ancestral virus was able to systemically infect Ler-0 plants although the infection was asymptomatic. After 17 serial passages, the resulting virus (labeled as TEV-At17) accumulated to levels three orders of magnitude more than the ancestral virus per gram of infected tissue, its infectivity was $100 \%$ (compared with the low $10 \%$ of the ancestral genotype) and it induced severe symptoms including stunting, etching, and leaf malformation. A single amino acid substitution in the VPg was enough to trigger these symptoms. TEV-At17 infection caused the differential expression of a total of 505 up-regulated and 1335 down-regulated plant genes relative to its ancestor virus (Figure 3 in Literature citation 6). Both viruses also differentially affected the expression of transcription factors, with 51 up-regulated and 84 down-regulated only by the evolved virus. Interestingly, only genes up-regulated by the ancestral virus and unaffected by the evolved virus were significantly enriched in categories related to plant responses to different abiotic and biotic stresses, including systemic acquired resistance and activation of the innate immune resistance.

At face value, the above results support the hypothesis that by adapting to a host, viruses should change and improve the way they interact with the components of the host cell transcriptional network. Therefore, studies of virus-plant interactions should concentrate on naturally coevolved pairs rather than ad hoc pairs. While keeping in mind this consideration, global profiling experiments will allow identification of sets of genes that are essential for the replication of a given virus, but also other sets that may be required for closely relative viruses and even for unrelated viruses. Furthermore, if all these genes are placed into the context of host regulatory networks, we may identify pathways, rather than individual genes, that may be targets of intervention for therapeutics without undesired side effects.

\section{WHOLE VIRUS GENOME ANALYSIS: CASE STUDY OF CITRUS TRISTEZA VIRUS}

Repeated infections of perennial hosts often result in mixed infections by multiple strains of the same virus or related viruses $(8,92,110,131,143,144)$. This occurs, to a lesser extent, in annual crops as well $(31,98,112)$. Natural viral complexes create an environment that is conducive to high frequencies of recombination, and consequently appearance of an enormous collection of genetic variants that have potentials to evolve into novel genotypes or strains. In addition, functional complementation of viral proteins in such an environment may nurture mutations that could have been negatively selected in single infections. Studying such complex systems may require novel experimental approaches. An example of these approaches is the analyses of whole genome Citrus tristeza virus (CTV) complexes by high throughput genomic sequencing of viral populations $(144,150)$. These analyses have revealed detailed, genome-wide information on virus recombination, mutation, and evolution.

CTV, one of the largest plant viruses, is encoded by a positivesense ssRNA molecule of 19.2 to $19.3 \mathrm{~kb}$. Its transmission is through vegetative grafting and by aphids in a semipersistent manner. Its natural host, citrus, is propagated by budwood grafting and has a longevity of more than one hundred years. Repeated transmissions by aphids and vegetative propagation have resulted in an increase in the complexity of CTV populations over hundreds of years. The initial infection may have originated from 
a single strain, but subsequent infections by different strains occurred during the long history of human cultivation of citrus species, resulting in the co-existence of multiple strains (genotypes) in a single host. Similar scenarios of viral accumulation and consequently the existence of viral complexes with multiple strains are common in other viruses that persistently infect perennial, long living trees (81). Within CTV complexes, promiscuous recombination between genomes occurred at remarkably high rates $(143,144)$. Recent data also suggest extraordinary stability and low mutation rates of CTV (Z. Weng, W. O. Dawson, and Z. Xiong, unpublished data). These observations led to the hypothesis that the high level of promiscuous RNA recombination compensates for the extreme genome stability and low mutation rate of $\mathrm{CTV}$, and functions as a major force driving the production of genetic variants important for adaptation and evolution. These variants can be selected upon in a new environment and can potentially evolve to become an emerging viral strain. This hypothesis perhaps explains the origin of the sequenced CTV SY568 genome (152), which consists of mosaic sequences from severe and mild strains (143).

To study these complexes, a high density CTV resequencing microarray was designed to simultaneously resequence multiple genotypes in CTV populations with high accuracy (Fig. 3) (144, 150). A large number of natural isolates and single-aphid transmitted isolates have been analyzed using this array. Nearly all of the isolates, even some single-aphid-transmitted isolates, were found to contain more than one strain (144). The resequencing microarray provided direct visual identification of multiple components in a mixed infection and at the same time resequenced the predominant viral sequences in the complex.

This whole genome strategy further showed that CTV complexes comprised one or more predominant genotypes, with one or more genotypes as minor components. For example, a severe stem-pitting isolate from Florida, FL278, contains a predominant T30-like strain. T30 is a mild strain that causes little or no symptoms and does not cause significant economic damage (7), which does not agree with the severity of the disease observed in the source plant. Further analysis using the CTV resequencing microarray and real-time PCR revealed a minor genotype $(<1 \%$ of the population) that resembles a type T36 strain (Table 2), a quick-decline strain that is commonly associated with rapid death of trees on sour orange rootstock (82). The presence of this unusual CTV strain raises a possibility that the T36-like strain may in fact be a contributor to the observed stem-pitting symptoms. This example illustrates that a minor component in a CTV complex can play a significant role in pathogenesis. A thorough knowledge of the genetic composition within a CTV isolate is therefore critical to understanding the interaction among different genotypes in a disease complex and their roles in disease development.

Evidence for CTV recombination has been documented before $(83,97,119,143)$. As high as $4 \%$ of cloned viral genome fragments have been found to be recombinants between two co-infecting strains (143). However, these studies examined only select regions of the large CTV genome. When the recombination analysis is extended to the entire CTV genome by whole genome sequencing analysis, the scale and the degree of promiscuous recombination between co-infecting strains are even more astonishing. For instance, a natural field isolate, FS2-2, contains a CTV complex harboring three distinct strains that are visually identifiable in the hybridized resequencing microarray (144) (Fig. 3). A genomewide 454 sequencing analysis of FS2-2 revealed that a large number of 454 sequencing reads $(5 \%)$ were recombinants, despite the fact that these sequences were relatively short, with an

\begin{tabular}{|c|c|c|}
\hline \multicolumn{3}{|c|}{$\begin{array}{c}\text { TABLE } 2 \\
\begin{array}{c}\text { Amounts }(\mathrm{fg})^{\mathrm{a}} \text { of Citrus tristeza virus (CTV) strains } \\
\text { in CTV complexes }\end{array}\end{array}$} \\
\hline \multirow[b]{2}{*}{ Strains } & \multicolumn{2}{|c|}{ CTV complex } \\
\hline & FS2-2 & FL278 \\
\hline VT-like & $155.9 \pm 9.9$ & N/A \\
\hline T30-like & $37.1 \pm 4.4$ & $86.28 \pm 7.7$ \\
\hline T36-like & $62.0 \pm 12.4$ & $0.43 \pm 0.2$ \\
\hline \multicolumn{3}{|c|}{$\begin{array}{l}\text { a The amount in fg of CTV cDNA in } 1 \mu \mathrm{g} \text { of tissues calculated using } \\
\text { standard curves generated for each genotype ( } Z \text {. Xiong and } \\
Z \text {. Weng, unpublished data). }\end{array}$} \\
\hline
\end{tabular}
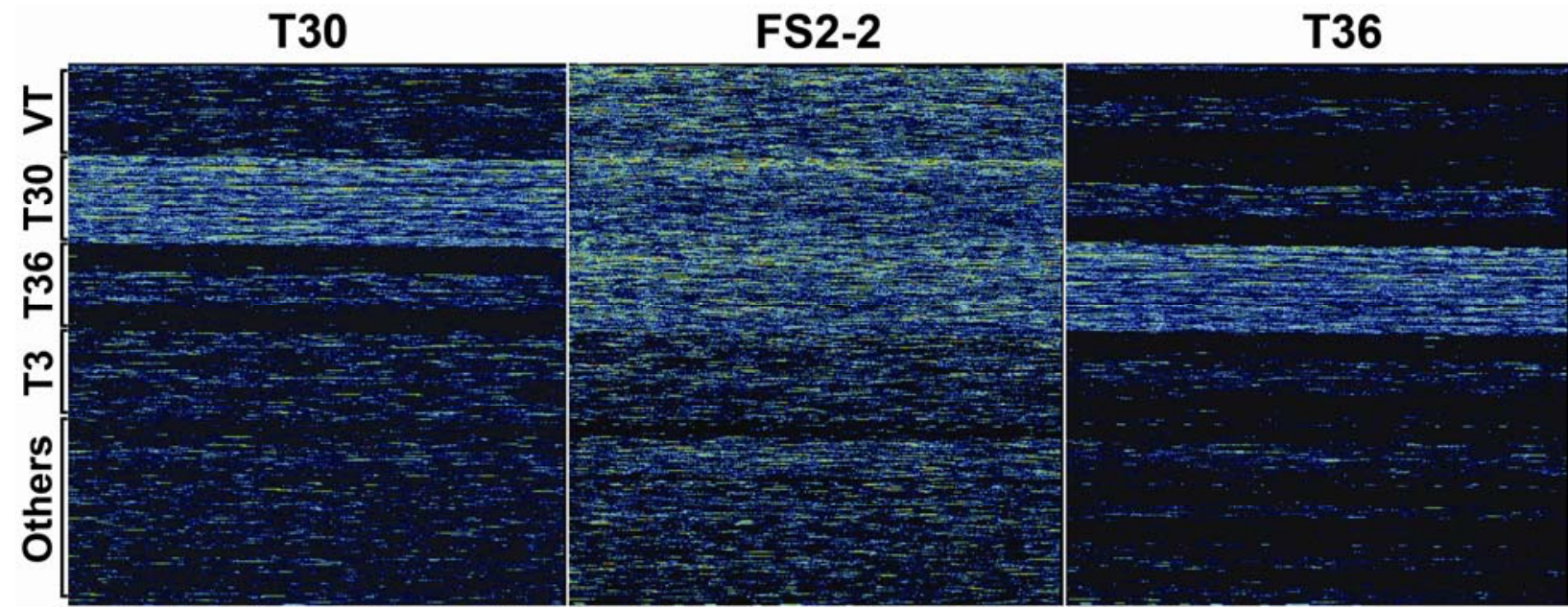

\section{FIGURE 3}

Images of hybridized resequencing microarrays showing multiple strains in isolate FS2-2. The Citrus tristeza virus (CTV) Affymetrix microarray chips were hybridized with target DNA prepared from full-length clones of T30 and T36 strains and from full genomic DNA of FS2-2 amplified by reverse transcription-polymerase chain reaction. Warm colors represent higher hybridization intensities and cool colors represent lower hybridization intensities. Locations of CTV genomes tiled on the microarray are indicated to the left. 
average length of 256 nucleotides. The recombination events were throughout the entire genome, with the most active recombination occurring toward the $3^{\prime}$ half of the CTV genome. FS2-2 contains at least three co-infecting strains: T30, T36, and VT. Promiscuous recombination occurred among all the identified strains. A deeper analysis of 1-kb genomic fragments, sequenced by the traditional Sanger method, corroborated the high level of recombination activity in the FS2-2 complex. A surprisingly large percentage (17.9\%) of the cloned molecules was found to be recombinants between the three constituent strains. Additionally, four recombinants possessed two crossover sites, resulting from either a double-crossover or two independent recombination events (144). Further divergence of some recombinants after recombination was also evident in this study. Thus, these data suggest that promiscuous, intergenic recombination can generate a large amount of genetic variants, which could subsequently diverge and evolve to distinct CTV genotypes.

An interesting phenomenon in mixed infections of CTV is the lack of apparent cross protection and interference between multiple strains. Even though the $3^{\prime}$ halves of multiple CTV genomes within an infected plant share $90 \%$ or higher sequence identity, they replicate independently and do not seem to interfere with each other. The inability of the predominant mild T30-like genotype in the above FL278 example to mitigate the effect of the severe T36-like genotype illustrates this failed cross-protection. Nevertheless, successful cross-protection using mild isolates can be achieved (140). Therefore, it is plausible that only strains with highly similar sequences across the entire genome protect against each other, or that in some cases the powerful, three-component RNA silencing suppression system in CTV $(50,91)$ somehow circumvents the effect of cross protection. Further genome-wide characterization of CTV complexes and other plant viruses will likely shed light on this important yet puzzling biological phenomenon, and provide guidance on effective implementation of cross protection and gene silencing strategies.

\section{INTEGRATION INTO DISEASE MANAGEMENT STRATEGIES}

Theoretically, an assembly of measures that altogether reduce the effective population size $\left(N_{e}\right)$, increase the genetic diversity, and maximize the bottleneck effect could gradually exclude a virus from its host species (i.e., virus exclusion $=$ small $N_{e}+$ large $\pi+$ low MOI). Unfortunately, the quantification of each one of these parameters is labor intensive, and the magnitude required to obtain the expected effect have not been empirically determined. $N_{e}$ is generally lower than the census of the population, $N$, and requires co-inoculation experiments to be estimated. On the other hand, $N$ can be directly estimated by ELISA or real-time PCR and, for practical purposes, it may follow the same trend as $N_{e}$ in some virus-plant interactions. A greater technological challenge is to develop a more feasible approach of estimating $\pi$ than the traditional cloning and sequencing. Technological advances such as next generation sequencing systems (15) may provide part of the solution to this task. Significant advancement has been made estimating bottleneck sizes at both ecological and intra-host levels, but these calculations may still need to include the population proportions that represent the estimated MOI. Plant resistance genes may affect $N_{e}$, $\Pi$, or MOI in the desired way. However, few $R$ genes, other than $R z 1$ and $R z 2$ affecting $\pi$ in sugar beet, have been quantitatively characterized in relation to some of these parameters $(21,49)$. Antivirals based on nucleotide analogs increase $\pi$ enough to drive the population into lethal mutagenesis (27), but their economic cost and environmental safety in agriculture still need to be evaluated. More viable antiviral strategies may be those based on natural plant resistance mechanisms such as gene silencing or those involving posttranscriptional enzymatic modifications of virus nucleotides.

In addition to the genetic plant restriction of virus cell-to-cell and vascular movements, bottleneck narrowing could be achieved by reducing the number of initial infection events to which a plant or plant population is exposed. Traditionally, it has been assumed that the amount of virus particles inoculated in a susceptible plant is epidemiologically irrelevant (57), but it might not be true for some incompatible virus-plant interactions, mainly those where the frequency of virulent genomes is constrained by intrapopulation interactions.

The host environment influences viral population variability by controlling co-infection dynamics, which determine the potential for complementation and recombination (147). Therefore, the role that alternate host reservoirs may have in the generation of virus variation should be taken in consideration during disease risk assessments.

Trans-complementation among different versions of the same viral element expressed in a common cellular compartment may improve virus robustness through direct reciprocity (e.g., a defective transporter could benefit from an efficient replicator and vice versa) (136). A practical consequence of modeling virus robustness is that, under mutagenic conditions imposed by the host or external mutagens, some virus populations could be eradicated through lethal mutagenesis whereas others would recover following the generation-selection of RB mutations. Serial passage of wild type BNYVV through strongly resistant $R z 2$ sugar beets caused an increase of its genetic heterogeneity to such levels that, in some lineages, the virus infection was gradually eliminated while in others its apparent robustness was improved (1).

The relationship between virus fitness and the $\pi_{W} / \pi_{B}$ ratio describe in Figure 2 suggests that, if a virus has reach the adapted stage without causing significant damage to the crop, it most likely will persist in that condition for a long time. Therefore, engaging in a two-arm race with the virus to eradicate the disease may not be a profitable strategy. In conclusion, plant viruses and viroids have become important experimental systems for studying pathogen evolution, and an increasing amount is known about their mutation, recombination, and evolutionary dynamics. The ways in which populations of viruses interact with one or a number of hosts has begun to be probed using high-throughput techniques, and is revealing how small fractions of an infecting population might be driving symptom severity, how rapid viral adaptation to a novel host leads to massive changes in host response to the virus, and how periodically the hosts that permit the lowest viral titers harbor the greatest viral population diversity. These insights are helping to explain the field data, which often show very little change in viral sequences despite large changes in symptoms, host range, and disease severity. Future work will continue to expand our basic knowledge of phytopathology and direct applied research into how best to control viral and viroid population diversity, effective population size and limit pathogen spread.

\section{ACKNOWLEDGMENTS}

R. Acosta-Leal thanks C. M. Rush (AgriLife, Amarillo, TX) for research counseling, and R. L. Jordan (USDA-ARS, MPPL), R. A. Naidu (Washington State University), S. Adkins (USDA-ARS, USHRL), W. L. Schneider (USDA-ARS, Fort Detrick, MD), and R. Wilkie (APS, St. Paul, MN) for logistic support in the realization of the originating symposium. S. Duffy was supported by the NJ Agricultural Experiment Station. S. F. Elena was supported by grants from the Spanish Ministerio de Ciencia e Innovación (BFU2009-06993) and Generalitat Valenciana (PROMETEO2010/019). Work on CTV was supported by funding from USDA grants 2003-34399-13764 and 2005-34399-16070 to Z. Xiong. 
Work on BNYVV was funded by The Minnesota-North Dakota Research and Education Board, and The Beet Sugar Development Foundation. R. W. Hammond thanks J. M. Crosslin (USDA-ARS, VFGRU) for critical reading of the manuscript.

\section{LITERATURE CITED}

1. Acosta-Leal, R., Bryan, K. B., and Rush, C. M. 2010. Host effect on the genetic diversification of Beet necrotic yellow vein virus single-plant populations. Phytopathology 100:1204-1212.

2. Acosta-Leal, R., Bryan, K. B., Smith, J. T., and Rush, C. M. 2010. Breakdown of host resistance by independent evolutionary lineages of Beet necrotic yellow vein virus involves a parallel C/U mutation in its $p 25$ gene. Phytopathology 100:127-133.

3. Acosta-Leal, R., Fawley, M. W., and Rush, C. M. 2008. Changes in the intra-isolate genetic structure of Beet necrotic yellow vein virus populations associated with plant resistance breakdown. Virology 376:60-68

4. Acosta-Leal, R., and Xiong, Z. 2008. Complementary functions of two recessive $R$-genes determine resistance durability of tobacco 'Virgin A Mutant' (VAM) to Potato virus Y. Virology 379:275-283.

5. Agudelo-Romero, P., Carbonell, P., De la Iglesia, F., Carrera, J., Rodrigo, G., Jaramillo, A., Pérez-Amado, M. A., and Elena, S. F. 2008. Changes in the gene expression profile of Arabidopsis thaliana after infection with Tobacco etch virus. Virol. J. 5:92.

6. Agudelo-Romero, P., Carbonell, P., Pérez-Amador, M. A., and Elena, S. F. 2008. Virus adaptation by manipulation of host's gene expression. PLoS ONE 3:e2397.

7. Albiach-Martí, M. R., Mawassi, M., Gowda, S., Satyanarayana, T., Hilf, M. E., Shanker, S., Almira, E. C., Vives, M. C., Lopez, C., Guerri, J., Flores, R., Moreno, P., Garnsey, S. M., and Dawson, W. O. 2000. Sequences of Citrus tristeza virus separated in time and space are essentially identical. J. Virol. 74:6856-6865.

8. Al Rwahnih, M., Daubert, S., Golino, D., and Rowhani, A. 2009. Deep sequencing analysis of RNAs from a grapevine showing Syrah decline symptoms reveals a multiple virus infection that includes a novel virus. Virology 387:395-401.

9. Ambrós, S., Hernández, C., Desvignes, J. C., and Flores, R. 1998. Genomic structure of three phenotypically different isolates of peach latent mosaic viroid: Implication of the existence of constraints limiting the heterogeneity of viroid quasispecies. J. Virol. 72:7397-7406.

10. Ascencio-Ibáñez, J. T., Sozzani, R., Lee, T. J., Chu, T. M., Wolfinger, R. D., Cella, R., and Hanley-Bowdoin, L. 2008. Global analysis of Arabidopsis gene expression uncovers a complex array of changes impacting pathogen response and cell cycle during geminivirus infection. Plant Physiol. 148:436-454.

11. Ayllón, M. A., Rubio, L., Moya, A., Guerri, J., and Moreno, P. 1999. The haplotype distribution of two genes of Citrus tristeza virus is altered after host change or aphid transmission. Virology 255:32-39.

12. Babu, M., Griffiths, J. S., Huang, T. S., and Wang, A. 2008. Altered gene expression changes in Arabidopsis leaf tissues and protoplasts in response to Plum pox virus infection. BMC Genomics 9:325.

13. Bailer, S. M., and Haas, J. 2009. Connecting viral with cellular interactomes. Curr. Opin. Microbiol. 12:453-459.

14. Barábasi, A. L., and Oltvai, Z. N. 2004. Network biology: Understanding the cell's functional organization. Nat. Rev. Genet. 5:101-113.

15. Bentley, D. R. 2006. Whole-genome re-sequencing. Curr. Opin. Gen. Develop. 16:545-552.

16. Briddon, R. W., Bull, S. E., Amin, I., Idris, A. M., Mansoor, S., Bedford, I. D., Dhawan, P., Rishi, N., Siwatch, S. S., Abdel-Salam, A. M., Brown, J. K., Zafar, Y., and Markham, P. G. 2003. Diversity of DNA beta, a satellite molecule associated with some monopartite begomoviruses. Virology 312:106-121.

17. Bull, J. J., Sanjuán, R., and Wilkie, C. O. 2007. Theory of lethal mutagenesis for viruses. J. Virol. 81:2930-2939.

18. Burch, C. L., and Chao, L. 2000. Evolvability of an RNA virus is determined by its mutational neighbourhood. Nature 406:625-628.

19. Calderwood, M. A., Venkatesan, K., Xing, L., Chase, M. R., Vazquez, A., Holthaus, A. M., Ewence, A. E., Li, N., Hirozane-Kishikawa, T., Hill, D. E., Vidal, M., Kieff, E., and Johannsen, E. 2007. Epstein-Barr virus and virus human protein interaction maps. Proc. Natl. Acad. Sci. USA 104:7606-7611.

20. Carrasco, P., de la Iglesia, F., and Elena, S. F. 2007. Distribution of fitness and virulence effects caused by single-nucleotide substitutions in tobacco etch virus. J. Virol. 81:12979-12984.

21. Chain, F., Riault, G., Trottet, M., and Jacquot, E. 2007. Evaluation of the durability of the Barley yellow dwarf virus-resistant Zhong ZH and TC14 wheat lines. Eur. J. Plant Pathol. 117:35-43.
22. Chare, E. R., and Holmes, E. C. 2004. Selection pressures in the capsid genes of plant RNA viruses reflect mode of transmission. J. Gen. Virol. 85:3149-3157.

23. Chare, E. R., and Holmes, E. C. 2006. A phylogenetic survey of recombination frequency in plant RNA viruses. Arch. Virol. 151:933-946.

24. Chateigner-Boutin, A. L., and Small, I. 2010. Plant RNA editing. RNA Biol. 7:213-219.

25. Chisholm, S. T., Mahajan, S. K., Whitham, S. A., Yamamoto, M. L., and Carrington, J. C. 2000. Cloning of Arabidopsis RTM1 gene, which controls restriction of long-distance movement of Tobacco etch virus. Proc. Natl. Acad. Sci. USA 97:489-494.

26. Codoñer, F. M., Daròs, J.-A., Sole, R. V., and Elena, S. F. 2006. The fittest versus the flattest: Experimental confirmation of the quasispecies effect with subviral pathogens. PLoS Pathog. 2:1187-1193.

27. Crotty, S., Cameron, C. E., and Andino, R. 2001. RNA virus error catastrophe: Direct molecular test by using ribavirin. Proc. Natl. Acad. Sci. USA 98:6895-6900.

28. Daròs, J.-A., Elena, S. F., and Flores, R. 2006. Viroids: And Ariadne's thread into the RNA labyrinth. EMBO Rep. 7:593-598.

29. De Chassey, B., Navratil, V., Tafforeau, L., Hiet, M. S., Aublin-Gex, A., Agaugué, S., Meiffren, G., Pradezynski, F., Faria, B. F., Chantier, T., Le Breton, M., Pellet, J., Davoust, N., Mangeot, P. E., Chaboud, A., Penin, F., Jacob, Y., Vidalain, P. O., Vidal, M., André, P., Rabourdin-Combe, C., and Lotteau, V. 2008. Hepatitis C virus infection protein network. Mol. Syst. Biol. 4:230.

30. De la Peña, M., and Flores, R. 2002. Chrysanthemum chlorotic mottle viroid RNA: Dissection of the pathogenicity determinant and comparative fitness of symptomatic and non-symptomatic variants. J. Mol. Biol. 321:411-421.

31. Díaz-Pendón, J. A., Canizares, M. C., Moriones, E., Bejarano, E. R., Czosnek, H., and Navas-Castillo, J. 2010. Tomato yellow leaf curl viruses: Ménage á trois between the virus complex, the plant, and the whitefly vector. Mol. Plant Pathol. 11:441-450.

32. Diener, T. O. 1971. Potato spindle tuber "virus". IV. A replicating, low molecular weight RNA. Virology 45:411-428.

33. Diener, T. O. 1989. Circular RNAs: Relics of precellular evolution? Proc. Natl. Acad. Sci. USA 86:9370-9374.

34. Diener, T. O. 2001. The viroid: Biological oddity or evolutionary fossil? Adv. Virus Res. 57:137-184.

35. Domingo-Calap, P., Cuevas, J. M., and Sanjuán, R. 2009. The fitness effects of random mutations in single-stranded DNA and RNA bacteriophages. PLoS Genet. 5:e1000742.

36. Drake, J. W., Charlesworth, B., Charlesworth, D., and Crow, J. F. 1998. Rates of spontaneous mutations. Genetics 148:1667-1686.

37. Duffy, S., and Holmes, E. C. 2008. Phylogenetic evidence for rapid rates of molecular evolution in the single-stranded DNA begomovirus Tomato yellow leaf curl virus (TYLCV). J. Virol. 82:957-965.

38. Duffy, S., and Holmes, E. C. 2009. Validation of high rates of nucleotide substitution in geminiviruses: Phylogenetic evidence from East African cassava mosaic viruses. J. Gen. Virol. 90:1539-1547.

39. Duffy, S., Shackelton, L. A., and Holmes, E. C. 2008. Rates of evolutionary change in viruses: Patterns and determinants. Nat. Rev. Genet. 9:267-276.

40. Duffy, S., Turner, P. E., and Burch, C. L. 2006. Pleiotropic costs of niche expansion in the RNA bacteriophage Phi 6. Genetics 172:751-757.

41. Durán-Vila, N., Elena, S. F., Darós, J. A., and Flores, R. 2008. Structure and evolution of viroids. Pages 43-64 in: Origin and Evolution of Viruses. E. Domingo, C. R. Parrish, and J. J. Holland, eds. Academic Press, London.

42. Dyer, M. D., Murali, T. M., and Sobral, B. W. 2008. The landscape of human proteins interacting with viruses and other pathogens. PLoS Pathog. 4:e32.

43. Elena, S. F., Agudelo-Romero, P., Carrasco, P., Codoñer, F. M., Martin, S., Torres-Barcelo, C., and Sanjuán, R. 2008. Experimental evolution of plant RNA viruses. Heredity 100:478-483.

44. Elena, S. F., Carrasco, P., Darós, J. A., and Sanjuán, R. 2006. Mechanisms of genetic robustness in RNA viruses. EMBO Rep. 7:168-173.

45. Elena, S. F., Carrera, J., and Rodrigo, G. 2011. A systems biology approach to the evolution of plant-virus interactions. Curr. Opin. Plant Biol. doi:10.1016/j.pbi.2011.03.013.

46. Elena, S. F., Gómez, G., and Daròs, J.-A. 2009. Evolutionary constraints to viroid evolution. Viruses 1:241-254.

47. Elena, S. F., and Sanjuán, R. 2005. Adaptive value of high mutation rates of RNA viruses: Separating causes from consequences. J. Virol. 79:11555-11558.

48. Espinoza, C., Medina, C., Somerville, S., and Arce-Jonhson, P. 2007. Senescence-associated genes induced during compatible viral interactions with grapevine and Arabidopsis. J. Exp. Bot. 58:3197-3212. 
49. Fabre, F., Brouchou, C., Palloix, A., and Moury, B. 2009. Key determinants of resistance durability to plant viruses: Insights from a model linking within- and between-host dynamics. Virus Res. 141:140-149.

50. Fagoaga, C., López, C., de Mendoza, A. H., Moreno, P., Navarro, L., Flores, R., and Peña, L. 2006. Post-transcriptional gene silencing of the p23 silencing suppressor of Citrus tristeza virus confers resistance to the virus in transgenic Mexican lime. Plant Mol. Biol. 60:153-165.

51. Fargette, D., Pinel, A., Abubakar, Z., Traoré, O., Brugidou, C., Fatogoma, S., Hébrard, E., Choisy, M., Séré, Y., Fauquet, C., and Konaté, G. 2004. Inferring the evolutionary history of Rice yellow mottle virus from genomic, phylogenetic, and phylogeographic studies. J. Virol. 78:3252-3261.

52. Fargette, D., Pinel, A., Rakotomalala, M., Sangu, E., Traoré, O., Sérémé, D., Sorho, F., Issaka, S., Hébrard, E., Séré, Y., Kanyeka, Z., and Konaté, G. 2008. Rice yellow mottle virus, an RNA plant virus, evolves as rapidly as most RNA animal viruses. J. Virol. 82:3584-3589.

53. Ferris, M. T., Joyce, P., and Burch, C. L. 2007. High frequency of mutations that expand the host range of an RNA virus. Genetics 176:1013-1022.

54. Fossum, E., Friedel, C. C., Rajagopala, S. V., Titz, B., Baiker, A., Schmidt, T., Kraus, T., Stellberger, T., Rutenberg, C., Suthram, S., Bandyopadhyay, S., Rose, D., von Brunn, A., Uhlmann, M., Zeretzke, C., Dong, Y. A., Boulet, H., Koegl, M., Bailer, S. M., Koszinowski, U., Ideker, T., Uetz, P., Zimmer, R., and Haas, J. 2009. Evolutionarily conserved herpesviral protein interaction networks. PLoS Pathog. 5:e1000570.

55. Fraile, A., Malpica, J. M., Aranda, M. A., Rodríguez-Cerezo, E., and García-Arenal, F. 1996. Genetic diversity in tobacco mild green mosaic tobamovirus infecting the wild plant Nicotiana glauca. Virology 223:148155.

56. Fregene, M., Matsumura, H., Akano, A., Dixon, A., and Terauchi, R. 2004. Serial analysis of gene expression (SAGE) of host-plant resistance to the cassava mosaic disease (CMD). Plant Mol. Biol. 56:563-571.

57. French, R., and Stenger, D. C. 2003. Evolution of Wheat streak mosaic virus: Dynamics of population growth within plants may explain limited variation. Annu. Rev. Phytopathol. 41:199-214.

58. French, R., and Stenger, D. C. 2005. Population structure within lineages of Wheat streak mosaic virus derived from a common founding event exhibits stochastic variation inconsistent with the deterministic quasispecies model. Virology 343:179-189.

59. Froissart, R., Roze, D., Uzest, M., Galibert, L., Blanc, S., and Michalakis, Y. 2005. Recombination every day: Abundant recombination in a virus during a single multi-cellular host infection. PLoS Biol. 3:e89.

60. Froissart, R., Wilke, C. O., Montville, R., Remold, S. K., Chao, L., and Turner, P. E. 2004. Co-infection weakens selection against epistatic mutations in RNA viruses. Genetics 168:9-19.

61. Gago, S., Elena, S. E., Flores, R., and Sanjuán, R. 2009. Extremely high mutation rate of a hammerhead viroid. Science 323:1308.

62. García-Arenal, F., Fraile, A., and Malpica, J. M. 2001. Variability and genetic structure of plant virus populations. Annu. Rev. Phytopathol. 39:157-186.

63. García-Arenal, F., Fraile, A., and Malpica, J. M. 2003. Variation and evolution of plant virus populations. Int. Microbiol. 6:225-232.

64. Geri, C., Cecchini, E., Giannakou, M. E., Covey, S. N., and Milner, J. J. 1999. Altered patterns of gene expression in Arabidopsis elicited by Cauliflower mosaic virus (CaMV) infection and by CaMV gene VI transgene. Mol. Plant-Microbe Interact. 12:377-384

65. Gibbs, A. J., Fargette, D., García-Arenal, F., and Gibbs, M. J. 2010. Time-The emerging dimension of plant virus studies. J. Gen. Virol. 91:13-22.

66. Gibbs, A. J., Gibbs, M., Ohshima, K., and García-Arenal, F. 2008. More about plant virus evolution: Past, present and future. Pages 229-250 in: Origin and Evolution of Viruses. E. Domingo, C. R. Parrish, and J. J. Holland, eds. Academic Press, London.

67. Gibbs, A. J., Ohshima, K., Phillips, M. J., and Gibbs, M. J. 2008. The prehistory of potyviruses: Their initial radiation was during the dawn of agriculture. PLoS ONE 3:e2523.

68. Golem, S., and Culver, J. N. 2003. Tobacco mosaic virus induced alterations in the gene expression profile of Arabidopsis thaliana. Mol. Plant-Microbe Interact. 16:681-688.

69. González-Jara, P., Fraile, A., Canto, T., and García-Arenal, F. 2009. The Multiplicity of infection of a plant virus varies during colonization of its eukaryotic host. J. Virol. 83:7487-7494.

70. Grigoras, I., Timchenko, T., Grande-Perez, A., Katul, L., Vetten, H. J., and Gronenborn, B. 2010. High variability and rapid evolution of a nanovirus. J. Virol. 84:9105-9117.

71. Guo, D., Rajamäki, M. L., Saarma, M., and Valkonen, J. P. T. 2001. Towards a protein interaction map of potyviruses: Protein interaction matrixes of two potyviruses based on the yeast two-hybrid system. J. Gen. Virol. 82:935-939.

72. Gutierrez, S., Yvon, M., Thebaud, G., Monsion, B., Michalakis, Y., and Blanc, S. 2010. Dynamics of the multiplicity of cellular infection in a plant virus. PLoS Pathog. 6(9):e1001113.

73. Hamilton, C. E., Papavasiliou, F. N., and Rosenberg, B. R. 2010. Diverse functions for DNA and RNA editing in the immune system. RNA Biol. 7:220-228

74. Hammond, R., Smith, D. R., and Diener, T. O. 1989. Nucleotide sequence and proposed secondary structure of Columnea latent viroid: A natural mosaic of viroid sequences. Nucleic Acids Res. 17:10083-10094.

75. Harkins, G., Delport, W., Duffy, S., Wood, N., Monjane, A. L., Owor, B. E., Donaldson, L., Saumtally, S., Verabudren, S., Triton, G., Markham, P. G., Briddon, R. W., Shepherd, D. N., Rybicki, E. P., Martin, D. P., and Varsani, A. 2009. Experimental evidence indicating that mastreviruses probably did not co-diverge with their hosts. Virol. J. 6:104

76. Holmes, E. C. 2009. The evolutionary genetics of emerging viruses. Annu. Rev. Ecol. Evol. Syst. 40:353-372.

77. Ishihara, T., Sakurai, N., Sekine, K. T., Hase, S., Ikegami, M., Shibata, D., and Takahashi, H. 2004. Comparative analysis of expressed sequence tags in resistant and susceptible ecotypes of Arabidopsis thaliana infected with Cucumber mosaic virus. Plant Cell Physiol. 45:470-480.

78. Janssen, D., Velasco, L., Martin, G., Segundo, E., and Cuadrado, I. 2006. Low genetic diversity among Cucumber vein yellowing virus isolates from Spain. Virus Genes 34:367-371.

79. Jenkins, G. M., Rambaut, A., Pybus, O. G., and Holmes, E. C. 2002. Rates of molecular evolution in RNA viruses: A quantitative phylogenetic analysis. J. Mol. Evol. 54:156-165.

80. Jockusch, H., Wiegand, C., Mersch, B., and Rajes, D. 2001. Mutants of Tobacco mosaic virus with temperature-sensitive coat proteins induce heat shock response in tobacco leaves. Mol. Plant-Microbe Interact. 14:914-917.

81. Jridi, C., Martin, J. F., Marie-Jeanne, V., Labonne, G., and Blanc, S. 2006. Distinct viral populations differentiate and evolve independently in a single perennial host plant. J. Virol. 80:2349-2357.

82. Karasev, A. V., Boyko, V. P., Gowda, S., Nikolaeva, O. V., Hilf, M. E., Koonin, E. V., Niblett, C. L., Cline, K., Gumpf, D. J., Lee, R. F., Garnsey, S. M., Lewandowski, D. J., and Dawson, W. O. 1995. Complete sequence of the Citrus tristeza virus RNA genome. Virology 208:511-520.

83. Kim, D. H., Shim, H. K., Hyeon, J. W., Kwon, H. M., Kim, K. S., Choi, M. S., Lee, J. K., Kim, D. G., Yang, J. S., and Lee, S. C. 2006. SSCP analysis of variations in haplotypes of Citrus tristeza virus isolated from yuzu (Citrus junos) in geographically separate regions of Korea. J. Plant Biol. 49:88-96.

84. Kitano, H. 2002. Systems biology: A brief overview. Science 295:16621664.

85. Koenig, R., and Lennefors, B. L. 2000. Molecular analyses of European $\mathrm{A}, \mathrm{B}$ and $\mathrm{P}$ type sources of Beet necrotic yellow vein virus and detection of the rare P type in Kazakhstan. Arch. Virol. 145:1561-1570.

86. Krishnan, M. N., Ng, A., Sukumaran, B., Gilfoy, F. D., Uchil, P. D., Sultana, H., Brass, A. L., Adametz, R., Tsui, M., Qian, F., Montgomery, R. R., Lev, S., Mason, P. W., Koski, R. A., Elledge, S. J., Xavier, R. J., Agaisse, H., and Fikrig, E. 2008. RNA interference screen for human genes associated with West Nile virus infection. Nature 455:242-245.

87. Lefeuvre, P., Lett, J. M., Reynaud, B., and Martin, D. P. 2007. Avoidance of protein fold disruption in natural virus recombinants. PLoS Pathog. 3:e181.

88. Li, H. Y., and Roossinck, M. J. 2004. Genetic bottlenecks reduce population variation in an experimental RNA virus population. J. Virol. 78:10582-10587.

89. Lin, L., Shi, Y., Luo, Z., Lu, Y., Zheng, H., Yan, F., Chen, J., Chen, J., Adams, M. J., and Wu, Y. 2009. Protein-protein interactions in two potyviruses using the yeast two-hybrid system. Virus Res. 142:36-40.

90. Llamas, S., Sandoval, C., Babin, M., Pogany, J., Bujarski, J. J., and Romero, J. 2004. Effect of the host and temperature on the formation of defective RNAs associated with Broad bean mottle virus Infection. Phytopathology 94:69-75.

91. Lu, R., Folimonov, A., Shintaku, M., Li, W. X., Falk, B. W., Dawson, W. O., and Ding, S. W. 2004. Three distinct suppressors of RNA silencing encoded by a $20-\mathrm{kb}$ viral RNA genome. Proc. Natl. Acad. Sci. USA 101:15742-15747.

92. Lunden, S., Meng, B. Z., Avery, J., and Qiu, W. P. 2010. Association of Grapevine fanleaf virus, Tomato ringspot virus and Grapevine rupestris stem pitting-associated virus with a grapevine vein-clearing complex on var. Chardonnay. Eur. J. Plant Pathol. 126:135-144.

93. MacPherson, J. I., Dikerson, J. E., Pinney, J. W., and Robertson, D. L. 2010. Patterns of HIV-1 protein interaction identify perturbed hostcellular subsystems. PLoS Comp. Biol. 6:e1000863. 
94. Malpica, J. Fraile, A., Moreno, I., Obies, C. I., Drake, J. W., and GarcíaArenal, F. 2002. The rate and character of spontaneous mutation in an RNA virus. Genetics 162:1505-1511.

95. Mansky, L. M., and Cunninham, K. S. 2000. Virus mutators and antimutators: Roles in evolution, pathogenesis, and emergence. Trends Genet. 16:512-517.

96. Marathe, R., Guan, Z., Anandalakshmi, R., Zhao, H., and DineshKumar, S. P. 2004. Study of Arabidopsis thaliana resistome in response to Cucumber mosaic virus infection using whole genome microarray. Plant Mol. Biol. 55:501-520.

97. Martín, S., Sambade, A., Rubio, L., Vives, M. C., Moya, P., Guerri, J., Elena, S. F., and Moreno, P. 2009. Contribution of recombination and selection to molecular evolution of Citrus tristeza virus. J. Gen. Virol. 90:1527-1538.

98. Mascia, T., Cillo, F., Fanelli, V., Finetti-Sialer, M. M., De Stradis, A., Palukaitis, P., and Gallitelli, D. 2010. Characterization of the interactions between Cucumber mosaic virus and Potato virus $Y$ in mixed infections in tomato. Mol. Plant-Microbe Interact. 23:1514-1524.

99. McBride, R. C., Ogbunugafor, C. B., and Turner, P. E. 2008. Robustness promotes evolvability of thermotolerance in an RNA virus. BMC Evol. Biol. 8:231.

100. Minskaia, E., Hertzig, T., Gorbalenya, A. E., Campanacci, V., Cambillau, C., Canard, B., and Ziebuhr, J. 2006. Discovery of an RNA virus $3^{\prime}->5^{\prime}$ exoribonuclease that is critically involved in coronavirus RNA synthesis. Proc. Natl. Acad. Sci. USA 103:5108-5113.

101. Miyashita, S., and Kishino, H. 2010. Estimation of the size of genetic bottlenecks in cell-to-cell movement of Soil-borne wheat mosaic virus and the possible role of the bottlenecks in speeding up selection of variations in trans-acting genes or elements. J. Virol. 84:1828-1837.

102. Morilla, G., Krenz, B., Jeske, H., Bejarano, E. R., and Wege, C. 2004. Tête à tête of Tomato yellow leaf curl virus and Tomato yellow leaf curl Sardinia virus in single nuclei. J. Virol. 78:10715-10723.

103. Moya, A., Rodríguez-Cerezo, E., and García-Arenal, F. 1993. Geneticstructure of natural-populations of the plant RNA virus Tobacco mild green mosaic virus. Mol. Biol. Evol. 10:449-456.

104. Ohshima, K., Akaishi, S., Kajiyama, H., Koga, R., and Gibbs, A. J. 2010. Evolutionary trajectory of Turnip mosaic virus populations adapting to a new host. J. Gen. Virol. 91:788-801.

105. Ooi, K., and Yahara, T. 1999. Genetic variation of geminiviruses: Comparison between sexual and asexual host plant populations. Mol. Ecol. 8:89-97.

106. Owens, R. A., Yang, G., Gundersen-Rindal, D., Hammond, R. W., Candresse, T., and Bar-Joseph, M. 2000. Both point mutation and recombination contribute to the sequence diversity of Citrus viroid III. Virus Genes 20:243-252.

107. Padidam, M., Sawyer, S., and Fauquet, C. M. 1999. Possible emergence of new geminiviruses by frequent recombination. Virology 265:218-225.

108. Pagán, I., Firth, C., and Holmes, E. C. 2010. Phylogenetic analysis reveals rapid evolutionary dynamics in the plant RNA virus genus tobamovirus. J. Mol. Evol. 71:298-307.

109. Pagán, I., Fraile, A., Fernández-Fueyo, E., Montes, N., Alonso-Blanco, C., and García-Arenal, F. 2010. Arabidopsis thaliana as a model for the study of plant-virus coevolution. Phil. Tras. R Soc. B 365:1983-1995.

110. Pantaleo, V., Saldarelli, P., Miozzi, L., Giampetruzzi, A., Gisel, A., Moxon, S., Dalmay, T., Bisztray, G., and Burgyan, J. 2010. Deep sequencing analysis of viral short RNAs from an infected Pinot Noir grapevine. Virology 408:49-56.

111. Patil, B. L., and Dasgupta, I. 2006. Defective interfering DNAs of plant viruses. Crit. Rev. Plant Sci. 25:47-64.

112. Perotto, M. C., Cafrune, E. E., and Conci, V. C. 2010. The effect of additional viral infections on garlic plants initially infected with Allexiviruses. Eur. J. Plant Pathol. 126:489-495.

113. Pita, J. S., Fondong, V. N., Sangare, A., Otim-Nape, G. W., Ogwal, S., and Fauquet, C. M. 2001. Recombination, pseudorecombination and synergism of geminiviruses are determinant keys to the epidemic of severe cassava mosaic disease in Uganda. J. Gen. Virol. 82:655-665.

114. Poulicard, N., Pinel-Galzi, A., Hebrard, E., and Fargette, D. 2009. Why Rice yellow mottle virus, a rapidly evolving RNA plant virus, is not efficient at breaking rymv1-2 resistance. Mol. Plant Pathol. 11:145-154.

115. Rodríguez-Cerezo, E., Elena, S. F., Moya, A., and García-Arenal, F. 1991. High genetic stability in natural populations of the plant RNA virus Tobacco mild Green mosaic virus. J. Mol. Evol. 32:328-332.

116. Rodríguez-Cerezo, E., and García-Arenal, F. 1989. Genetic heterogeneity of the RNA genome population of the plant virus U5-TMV. Virology 170:418-423.

117. Rojas, M. R. and Gilbertson, R. L. 2008. Emerging plant viruses: A diversity of mechanisms and opportunities. Pages 27-51 in: Plant Virus
Evolution. M. J. Roossinck, ed. Springer-Verlag, Berlin

118. Rouzine, I. M., Rodrigo, A., and Coffin, J. M. 2001. Transition between stochastic evolution and deterministic evolution in the presence of selection: General theory and application to virology. Microbiol. Mol. Biol. Rev. 65:151-185.

119. Rubio, L., Ayllón, M. A., Kong, P., Fernandez, A., Polek, M., Guerri, J., Moreno, P., and Falk, B. W. 2001. Genetic variation of Citrus tristeza virus isolates from California and Spain: Evidence for mixed infections and recombination. J. Virol. 75:8054-8062.

120. Sanjuán, R., Agudelo-Romero, P., and Elena, S. F. 2009. Upper-limit mutation rate estimation for a plant RNA virus. Biol. Lett. 5:394-396.

121. Sanjuán, R., Cuevas, J. M., Moya, A., and Elena, S. F. 2005. Epistasis and the adaptability of an RNA virus. Genetics 170:1001-1008.

122. Sanjuán, R., Moya, A., and Elena, S. F. 2004. The distribution of fitness effects caused by single-nucleotide substitutions in an RNA virus. Proc. Natl. Acad. Sci. USA 101:8396-8401.

123. Sanjuán, R., Nebot, M. R., Chirico, N., Mansky, L. M., and Belshaw, R. 2010. Viral mutation rates. J. Virol. 84:9733-9748.

124. Schneider, W. L., and Roossinck, M. J. 2001. Genetic diversity in RNA virus quasispecies is controlled by host-virus interactions. J. Virol. 75:6566-6571.

125. Schrag, S. J., Rota, P. A., and Bellini, W. J. 1999. Spontaneous mutation rate of measles virus: Direct estimation based on mutations conferring monoclonal antibody resistance. J. Virol. 73:51-54.

126. Seal, S. E., VandenBosch, F., and Jeger, M. J. 2006. Factors influencing begomovirus evolution and their increasing global significance: Implications for sustainable control. Crit. Rev. Plant Sci. 25:23-46.

127. Simmons, H. E., Holmes, E. C., and Stephenson, A. G. 2008. Rapid evolutionary dynamics of Zucchini yellow mosaic virus. J. Gen. Virol. 89:1081-1085.

128. Simon, A. E., Roossinck, M. J., and Havelda, Z. 2004. Plant virus satellite and defective interfering RNAs: New paradigms for a new century. Annu. Rev. Phytopathol. 42:415-437.

129. Sniegowski, P. D., Gerrish, P. J., Johnson, T., and Shaver, A. 2000. The evolution of mutation rates: Separating causes from consequences. BioEssays 22:1057-1066.

130. Stenger, D. C., Seifers, D. L., and French, R. 2002. Patterns of polymorphism in Wheat streak mosaic virus: Sequence space explored by a clade of closely related viral genotypes rivals that between the most divergent strains. Virology 302:58-70.

131. Susaimuthu, J., Tzanetakis, I. E., Gergerich, R. C., Kim, K. S., and Martin, R. R. 2008. Viral interactions lead to decline of blackberry plants. Plant Dis. 92:1288-1292.

132. Tan, S. L., Ganji, G., Paeper, B., Proll, S., and Katze, M. G. 2007. Systems biology and the host response to viral infection. Nat. Biotech. 25:1383-1389.

133. Tomimura, K., Spak, J., Katis, N., Jenner, C. E., Walsh, J. A., Gibbs, A. J., and Ohshima, K. 2004. Comparisons of the genetic structure of populations of Turnip mosaic virus in West and East Eurasia. Virology 330:408-423

134. Trinks, D., Rajeswaran, R., Shivaprasad, P. V., Akbergenov, R., Oakeley, E. J., Veluthambi, K., Hohn, T., and Pooggin, M. M. 2005. Suppression of RNA silencing by a geminivirus nuclear protein, AC2, correlates with transactivation of host genes. J. Virol. 79:2517-2527.

135. Tromas, N., and Elena, S. F. 2010. The rate and spectrum of spontaneous mutations in a plant RNA virus. Genetics 185:983-989.

136. Turner, P. E., and Chao, L. 1999. Prisoner's dilemma in an RNA virus. Nature 398:441-443.

137. Uetz, P., Dong, Y. A., Zeretzke, C., Atzler, C., Baiker, A., Berger, B., Rajagopala, S. V., Roupelieva, M., Rose, D., Fossum, E., and Haas, J. 2006. Herpesviral protein networks and their interaction with the human proteome. Science 311:239-242.

138. Uetz, P., Rajagopala, S. V., Dong, Y. A., and Haas, J. 2004. From ORFeomes to protein interaction maps in viruses. Genome Res. $14: 2029-2033$

139. Urbanowicz, A., Alejska, M., Formanowicz, P., Blazewicz, J., Fligerowicz, M., and Bujarski, J. J. 2005. Homologous crossover among molecules of Brome mosaic virus RNA1 and RNA2 segments in vivo. J. Virol. 79:5732-5742.

140. Vanvuuren, S. P., Collins, R. P., and Dagraca, J. V. 1993. Evaluation of Citrus tristeza virus isolates for cross protection of grapefruit in SouthAfrica. Plant Dis. 77:24-28.

141. Ventelon-Debout, M., Delalande, F., Brizard, J. P., Diemer, H., Van Dorsselaer, A., and Brugidou, C. 2004. Proteome analysis of cultivarspecific deregulations of Oryza sativa indica and $O$. sativa japonica cellular suspensions undergoing Rice yellow mottle virus infection. Proteomics 4:216-225 
142. Vives, M. C., Rubio, L., Galipienso, L., Navarro, L., Moreno, P., and Guerri, J. 2002. Low genetic variation between isolates of Citrus leaf blotch virus from different host species and of different geographical origins. J. Gen. Virol. 83:2587-2591.

143. Vives, M. C., Rubio, L., Sambade, A., Mirkov, T. E., Moreno, P., and Guerri, J. 2005. Evidence of multiple recombination events between two RNA sequence variants within a Citrus tristeza virus isolate. Virology 331:232-237.

144. Weng, Z., Barthelson, R., Gowda, S., Hilf, M. E., Dawson, W. O., Galbraith, D. W., and Xiong, Z. 2007. Persistent infection and promiscuous recombination of multiple genotypes of an RNA virus within a single host generate extensive diversity. PLoS ONE 2:e917.

145. Whitham, S. A., Quan, S., Chang, H. S., Cooper, B., Estes, B., Zhu, T., Wang, X., and Hou, Y. M. 2003. Diverse RNA viruses elicit the expression of common sets of genes in susceptible Arabidopsis thaliana plants. Plant J. 33:271-283.

146. Whitham, S. A., and Wang, Y. 2004. Roles for host factors in plant viral pathogenicity. Curr. Opin. Plant. Biol. 7:365-371.

147. Wintermantel, W. M., Cortez, A. A., Anchieta, A. G., GulatiSakhuja, A., and Hladky, L. L. 2008. Co-infection by two criniviruses alters accumulation of each virus in a host-specific manner and influences efficiency of virus transmission. Phytopathology 98: 1340-1345.

148. Wise, R. P., Moscou, M. J., Bogdanove, A. J., Whitham, S. A. 2007. Transcript profiling in host-pathogen interactions. Annu. Rev. Phytopathol. 45:329-369.

149. Wu, B., Melcher, U., Guo, X., Wang, X., Fan, L., and Zhou, G. 2008. Assessment of codivergence of mastreviruses with their plant hosts. BMC Evol. Biol. 8:335.

150. Xiong, Z., Barthelson, R., Weng, Z., and Galbraith, D. W. 2006. Designing and testing of a Citrus tristeza virus re-sequencing microarray. Proc. Int. Org. Citrus Virol. 16:11-22.

151. Yang, C., Guo, R., Jie, F., Nettleton, D., Peng, J., Carr, T., Yeakely, J. M., Fan, J. B., and Whitham, S. A. 2007. Spatial analysis of Arabidopsis thaliana gene expression in response to Turnip mosaic virus infection. Mol. Plant-Microbe Interact. 20:358-370.

152. Yang, Z. N., Mathews, D. M., Dodds, J. A., and Mirkov, T. E. 1999. Molecular characterization of an isolate of Citrus tristeza virus that causes severe symptoms in sweet orange. Virus Genes 19:131-142.

153. Zhong, X., Archuall, A. J., Amin, A. A., and Ding, B. 2008. A genomic map of viroid RNA motifs critical for replication and systemic trafficking. Plant Cell 20:35-47. 